\title{
Metabolic Impact of Body Fat Percentage Independent of Body Mass Index in Women with Obesity Remission After Gastric Bypass
}

\author{
Daniel Eriksson Hogling ${ }^{1}$ (D) $\cdot$ Jesper Bäckdahl ${ }^{1} \cdot$ Anders Thorell $^{2} \cdot$ Mikael Rydén $^{1} \cdot$ Daniel P. Andersson $^{1}$
}

Published online: 12 December 2019

(C) The Author(s) 2019

\begin{abstract}
Background/Objective Body mass index (BMI) is central when evaluating treatment effect after gastric bypass. The metabolic impact of BMI-independent differences in body fat percentage (BF\%) after gastric bypass is not fully understood. We compared metabolic and adipose tissue characteristics in women with high versus low BF\% independent of BMI after obesity remission following gastric bypass.

Subjects/Methods A cohort of 215 women was included at baseline. A total of 166 women were re-examined 2 years after gastric bypass, whereof 130 had obesity remission $\left(\mathrm{BMI}<30 \mathrm{~kg} / \mathrm{m}^{2}\right)$. Anthropometric parameters, blood pressure, and lipids were measured. Total and regional body fat mass was determined by dual-energy X-ray absorptiometry. Insulin sensitivity was assessed by homeostasis model assessment of insulin resistance (HOMA-IR) and hyperinsulinemic euglycemic clamp ( $M$ value). Adipocyte size and number were determined.

Results Of the 130 women with obesity remission, 64 had BF\% $\geq 35$ and $65<35$. Independent of BMI, high BF\% were associated with higher HOMA-IR $(P=0.021)$, lower $M$ value $(P=0.0046)$, higher triglycerides $(P=0.013)$, higher visceral/ total and android/gynoid fat mass ratios $(P=0.0032$ and 0.0003 respectively), and larger subcutaneous fat cell volume $(P<0.0001) 2$ years after gastric bypass. No differences in anthropometric measures, glucose, blood pressure, or fat cell number were observed.

Conclusions Independent of BMI, patients with higher BF\% displayed lower insulin sensitivity, higher triglyceride levels, central fat distribution, and larger subcutaneous adipocytes 2 years after gastric bypass. Thus, determination of BF\% provides additional information of metabolic characteristics at follow-up of non-obese patients after gastric bypass.
\end{abstract}

Keywords Bariatric surgery $\cdot$ Body mass index $\cdot$ Metabolic syndrome $\cdot$ Insulin sensitivity $\cdot$ Body fat $\cdot \mathrm{X}$-ray absorptiometry

Daniel Eriksson Hogling

daniel.eriksson.hogling@ki.se

Jesper Bäckdahl

jesper.backdahl@ki.se

Anders Thorell

anders.thorell@ki.se

Mikael Rydén

mikael.ryden@ki.se

Daniel P. Andersson

daniel.p.andersson@ki.se

1 Department of Medicine (H7), Karolinska Institutet, Karolinska University Hospital, Huddinge, 14186 Stockholm, Sweden

2 Department of Clinical Sciences, Danderyd Hospital \& Department of Surgery, Ersta Hospital, Karolinska Institutet, 116

91 Stockholm, Sweden

\section{Introduction}

Body mass index (BMI) is the standard anthropometric measure for the categorization of overweight and obesity [1]. However, the use of BMI entails several limitations since body fat content is insufficiently captured by BMI. High body fat percentage (BF\%), often defined as $\geq 35 \%$ in women, is reported in up to $50 \%$ of the population with a BMI within the non-obese range [2-5] and is linked to worse metabolic parameters [3,6] including disturbed glucose metabolism [7] and future risk of type 2 diabetes [8].

Bariatric surgery, such as Roux-en-Y gastric bypass (RYGB), remains the most effective treatment of obesity [9-11]. Selection criteria for bariatric surgery have been virtually unchanged since the early 1990s and are still based on BMI and comorbidity $[12,13]$. Postoperative BMI is central in the evaluation of treatment effect, and is the most frequently 
used measure to define outcome after bariatric surgery in randomized trials [14].

Weight loss induces favorable changes including improvement of metabolic parameters and adipose tissue function. Following RYGB, these improvements have been reported not only to be a normalization, but rather to reach "supranormal" levels $[15,16]$. Weight loss-independent metabolic improvements are seen after RYGB, mediated by factors such as gut hormones and bile acids [17]. Whether these favorable changes attenuate the impact of excess BF\% among patients in the non-obese range after bariatric surgery is not fully understood. In this study, we investigated if BMIindependent differences in $\mathrm{BF} \%$ are associated with differences in metabolic function, anthropometric measures, or adipose tissue characteristics in patients reaching a non-obese state after RYGB.

\section{Materials and Methods}

\section{Clinical Cohort and Surgical Procedure}

The cohort studied herein was combined from two clinical trials (NCT01785134 and NCT01727245 at clinicaltrials. gov) with a similar study design, and main outcomes have been reported $[18,19]$. Baseline characteristics of the entire cohort before and after weight loss have been presented previously [20]. Subjects with insulin, glitazone, or glucocorticoid treatment were excluded. All patients underwent RYGB. The length of the Roux-limb (alimentary limb) was typically $120 \mathrm{~cm}$ and the biliopancreatic limb $50 \mathrm{~cm}$.

\section{Clinical Examinations and Determination of Fat Cell Size}

All patients were investigated in the morning after fasting overnight. Anthropometric measures were obtained and BMI and waist-to-hip ratio (WHR) calculated. Subcutaneous adipose tissue samples were obtained by needle aspiration in the paraumbilical region under local anesthesia. Fat cell volume was determined through light microscopy after collagenase digestion as previously described [21]. Fat cell number in the android subcutaneous adipose tissue region (as defined below) was calculated by dividing the subcutaneous fat mass with average fat cell mass. Insulin sensitivity was determined in two ways: the homeostasis model assessment of insulin resistance (HOMA-IR) [22] and by hyperinsulinemic euglycemic clamp as described [23], quantified as mean glucose infusion rate during steady state plasma glucose and insulin concentrations ( $M$ value). Briefly, a 1.6 units $/ \mathrm{m}^{2}$ body surface area bolus dose of insulin was administered intravenously, followed by a continuous intravenous infusion of insulin (Actrapid, Novo Nordisk, Copenhagen, Denmark) at a rate of 0.12 units $/ \mathrm{m}^{2}$ body surface area/min during $2 \mathrm{~h}$ accompanied by a $200 \mathrm{mg} / \mathrm{ml}$ variable glucose infusion to maintain euglycemia $(4.5-5.5 \mathrm{mmol} / \mathrm{l})$. For normalization of the $M$ value for lean body mass, lean body mass was calculated as body weight $(\mathrm{kg})$ minus DXAmeasured body fat mass $(\mathrm{kg})$. Enzyme-linked immunosorbent assay was used to determine serum insulin levels (Mercodia, Uppsala, Sweden). Plasma concentrations of glucose, cholesterol, triglycerides (TG), high-density lipoprotein (HDL) cholesterol, and apo B/apo A1 ratio were analyzed by the chemistry laboratory at the Karolinska University Hospital. The Friedewald's formula was used to calculate low-density lipoprotein (LDL) cholesterol [24]. An automatic device (Omron M10-IT, Omron health care, Hoofddorp, the Netherlands) was used to measure blood pressure.

\section{Determination of Body Fat Mass and Distribution}

Dual-energy X-ray absorptiometry (DXA, GE Lunar iDXA, GE Healthcare, Madison, WI, USA) was used to determine body fat mass, $\mathrm{BF} \%$, and body fat distribution. The enCore software (version 14.10.022, GE Healthcare, Madison, WI, USA) enabled determination of android and gynoid fat mass. The software defines the android region between the pelvis cut line, a line $20 \%$ of the distance between the pelvis and neck cut line and laterally by the arm cut line. Visceral fat mass can be estimated by the CoreScan feature (GE Medical Systems, Chalfont St. Giles, UK). The software assesses estimated visceral adipose tissue (EVAT) mass within the android region by subtracting the android subcutaneous fat from the total android fat. Thus, EVAT only refers to the visceral fat in the android region. Calibration checks of the DXA machine were performed daily.

\section{Statistical Analyses}

Continuous variables are described as mean \pm standard deviations. For between-group comparisons, unpaired two-sided $t$ test was used for normally distributed parameters and MannWhitney $U$ test for parameters not normally distributed. Normal distribution was assessed by Shapiro-Wilks test. Multiple regression analyses were used to adjust for residual differences in BMI and age, and to compare different independent variables versus $M$ value. In the former analyses, an interaction term between the independent variables was tested for. $P$ values $<0.05$ were considered statistically significant. JMP Version 13 (SAS Institute Inc., Cary, NC, USA) was used for all statistical analyses. 


\section{Results}

\section{Clinical Characteristics}

A total of 215 women were included at baseline before surgery, and $166(77.2 \%)$ were followed up 2 years after RYGB. Clinical characteristics of the cohort $(n=166)$ at baseline and after weight loss have been reported previously [20]. Mean BMI at baseline was $40.5 \pm 4.2 \mathrm{~kg} / \mathrm{m}^{2}$ and age $42.6 \pm 9.5$ years. A total of 130 women had achieved obesity remission (BMI< $30 \mathrm{~kg} / \mathrm{m}^{2}$ ) at follow-up. Of the 130 women with obesity remission, 64 had $\mathrm{BF} \% \geq 35$ and 65 had $\mathrm{BF} \%<35$, while one woman did not perform the DXA examination (Fig. 1). The relationship between BMI and BF\% after RYGB shown in Fig. 2 illustrates the BMI-independent variance in $\mathrm{BF} \%$. $\mathrm{BF} \%$ at baseline for the 130 patients with obesity remission at follow-up was $51.6 \pm 3.7(52.5 \pm 3.7$ for the high $\mathrm{BF} \%$ and $50.9 \pm 3.5$ for the low BF\% group, $P=0.015$ ). Before RYGB, 35 of the 130 patients with obesity remission at follow-up were on anti-hypertensive treatment, three patients treated with metformin, and eight with lipid-lowering drugs. At the follow-up, 18 had anti-hypertensive drugs, none remained on metformin, and three still had lipid-lowering treatment. A total of 20 patients had undergone omentectomy in addition to RYGB. Omentectomy in addition to RYGB has been shown not to affect metabolic outcome $[18,19]$. In patients with obesity remission, data on $M$ value was missing in 21 individuals, and data on fat cell volume in eight patients.

\section{Metabolic Profile and Adipose Tissue Characteristics in Women with High Versus Low Body Fat Percentage 2 Years After RYGB}

None of the women with obesity (BMI $\geq 30 \mathrm{~kg} / \mathrm{m}^{2}$ ) at followup 2 years after RYGB had BF\% < 35 (Fig. 2), and only women with obesity remission were included in further analyses. Clinical, metabolic, anthropometric, and adipose parameters were compared between those with high $\mathrm{BF} \%(\geq 35)$ and low $\mathrm{BF} \%(<35)$ and are presented in Table 1. Unadjusted analyses showed that the group with higher fat mass was

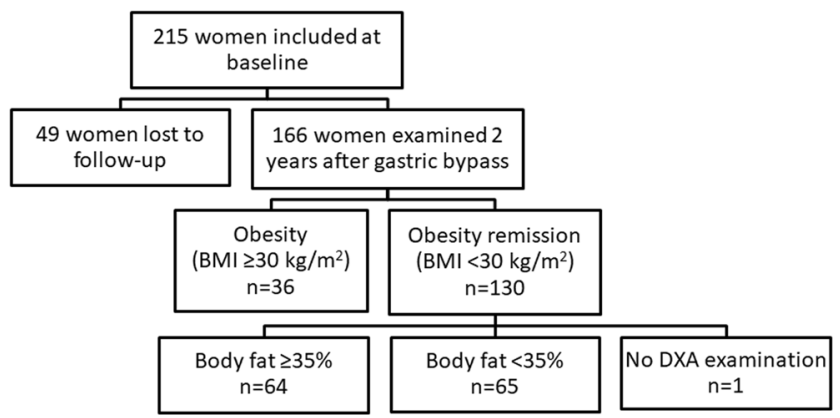

Fig. 1 Flow chart of patients included in the study. BMI, body mass index; DXA, dual-energy X-ray absorptiometry

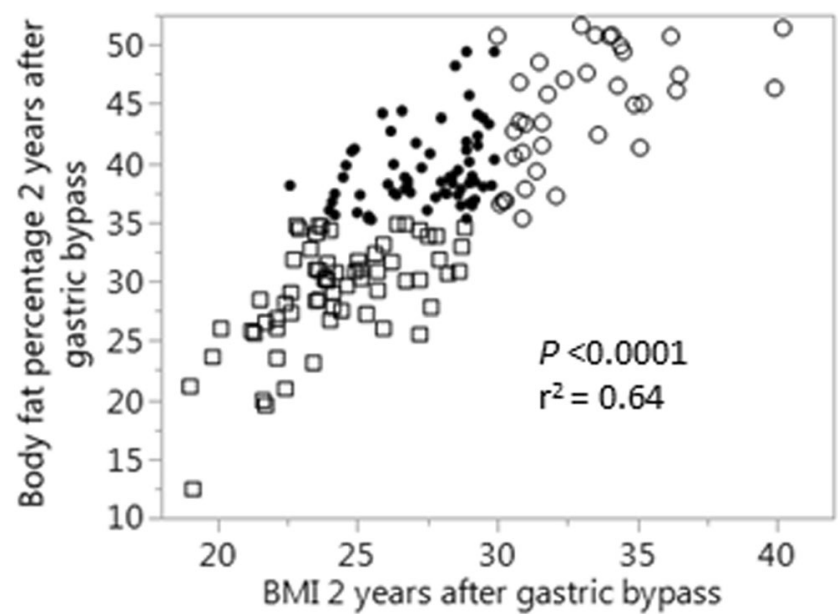

Fig. 2 Body mass index (BMI) in relation to body fat percentage (BF\%) 2 years after gastric bypass. Squares $=\mathrm{BF} \%<35$; dots $=\mathrm{BF} \% \geq 35$ and $\mathrm{BMI}<30 \mathrm{~kg} / \mathrm{m}^{2}$, circles $=\mathrm{BMI} \geq 30 \mathrm{~kg} / \mathrm{m}^{2} . P$ and $r^{2}$ values from linear regression analysis

characterized by older age, higher weight, BMI, glucose, insulin, HOMA-IR, total cholesterol, waist circumference, waist-to-hip ratio, android-to-gynoid and EVAT-to-total fat mass ratios, and larger subcutaneous fat cell volume and number as well as lower $M$ value expressed per total body mass but not per lean body mass (Table 1). After adjustment for the difference in BMI using multiple regression analyses, patients with obesity remission and high $\mathrm{BF} \%$ had higher insulin concentration $(P=0.044)$, HOMA-IR $(P=0.021)$, TG concentration $(P=0.013)$, subcutaneous fat cell volume $(P<0.0001)$, and android-to-gynoid as well as EVAT-to-total fat mass ratios ( $P=0.0032$ and 0.0003 respectively), and the $M$ value expressed per body mass remained lower $(P=0.0046)$, see Table 1 and Fig. 3. No statistically significant interactions were observed between independent variables (except for age where $P=0.20$ after including interaction), and interaction was therefore not considered in the adjusted model. Patients that were on medication for hyperlipidemia were excluded from the adjusted analyses of blood lipids, and patients with anti-hypertensive treatment were excluded from analyses of blood pressure. No statistically significant differences remained concerning age after adjustments for BMI, but after adjusting for both age and BMI in multiple regression analyses, the differences in HOMA-IR $(P=0.013), M$ value per total body mass $(P=0.049)$, subcutaneous fat cell volume $(P<0.0001)$, android-to-gynoid ratio $(P=0.0006)$, and EVAT-to-total fat mass ratio $(P=0.012)$ remained statistically significant, but not for insulin $(P=0.056)$. Given that no patient with low body fat had a BMI $>28.8 \mathrm{~kg} / \mathrm{m}^{2}$, and only one patient with high body fat had BMI below $24 \mathrm{~kg} / \mathrm{m}^{2}$ (see Figs. 2 and 3), we also performed analyses of BF\% versus the statistically significant outcomes in the group with BMI $24-28.8 \mathrm{~kg} / \mathrm{m}^{2}(n=75)$. BMI did not differ significantly between those with low and high body fat percentage in this 
Table 1 Clinical and adipose tissue characteristics of non-obese patients with high versus low body fat percentage 2 years after RYGB

\begin{tabular}{|c|c|c|c|c|c|}
\hline \multirow{3}{*}{$\begin{array}{l}\text { Clinical } \\
\text { characteristics } \\
2 \text { years after RYGB }\end{array}$} & \multirow{3}{*}{$\begin{array}{l}\text { Body fat }<35 \% \\
2 \text { years after RYGB } \\
(n=65)\end{array}$} & \multirow{3}{*}{$\begin{array}{l}\text { Body fat } \geq 35 \% \\
2 \text { years after } \\
\text { RYGB }(n=64)\end{array}$} & \multirow{3}{*}{$\begin{array}{l}\text { Unadjusted }^{\mathrm{a}} \\
P \text { value }\end{array}$} & \multicolumn{2}{|l|}{ Adjusted $^{\mathrm{b}}$} \\
\hline & & & & \multicolumn{2}{|l|}{$P$ value } \\
\hline & & & & $\begin{array}{l}\text { Body } \\
\text { fat } \%\end{array}$ & Interaction $^{\mathrm{c}}$ \\
\hline Age, years & $43.0 \pm 8.7$ & $46.4 \pm 10.4$ & 0.044 & 0.10 & 0.024 \\
\hline Weight, kg & $66.7 \pm 7.7$ & $74.5 \pm 7.7$ & $<0.0001$ & 0.94 & 0.92 \\
\hline BMI, $\mathrm{kg} / \mathrm{m}^{2}$ & $24.2 \pm 2.4$ & $27.4 \pm 2.4$ & $<0.0001$ & - & - \\
\hline Omentectomy, $n$ & 9 & 11 & $0.63^{\mathrm{d}}$ & 0.85 & 0.95 \\
\hline Glucose, mmol/1 & $4.9 \pm 0.4$ & $5.1 \pm 0.5$ & 0.030 & 0.17 & 0.077 \\
\hline Insulin, mU/1 & $4.1 \pm 1.4$ & $4.9 \pm 2.1$ & 0.0011 & 0.044 & 0.95 \\
\hline HOMA-IR & $0.89 \pm 0.31$ & $1.11 \pm 0.50$ & 0.0017 & 0.021 & 0.63 \\
\hline $\begin{array}{l}M \text { value, } \\
\mathrm{mg} / \mathrm{kg} \times \min \end{array}$ & $8.1 \pm 1.5$ & $7.1 \pm 1.5$ & 0.0006 & 0.0046 & 0.54 \\
\hline $\begin{array}{c}M \text { value, } \mathrm{mg} / \mathrm{kg} \text { lean } \\
\text { body mass } \times \text { min }\end{array}$ & $11.4 \pm 2.3$ & $11.4 \pm 2.4$ & 0.89 & 0.51 & 0.37 \\
\hline $\begin{array}{l}\text { Triglycerides, } \\
\mathrm{mmol} / 1\end{array}$ & $0.76 \pm 0.28$ & $0.91 \pm 0.34$ & 0.0066 & 0.013 & 0.080 \\
\hline Cholesterol, mmol/l & $3.9 \pm 0.7$ & $4.2 \pm 0.9$ & 0.021 & 0.088 & 0.11 \\
\hline $\begin{array}{l}\text { HDL cholesterol, } \\
\mathrm{mmol} / 1\end{array}$ & $1.59 \pm 0.31$ & $1.67 \pm 0.45$ & 0.44 & 0.74 & 0.97 \\
\hline $\begin{array}{l}\text { LDL cholesterol, } \\
\mathrm{mmol} / 1\end{array}$ & $1.96 \pm 0.58$ & $2.15 \pm 0.63$ & 0.059 & 0.17 & 0.12 \\
\hline Apo B/apo A1 ratio & $0.53 \pm 0.15$ & $0.56 \pm 0.19$ & 0.41 & 0.14 & 0.055 \\
\hline $\begin{array}{l}\text { Systolic blood } \\
\text { pressure, } \mathrm{mmHg}\end{array}$ & $119.8 \pm 15.1$ & $121.3 \pm 15.2$ & 0.62 & 0.85 & 0.18 \\
\hline $\begin{array}{l}\text { Diastolic blood } \\
\text { pressure, } \mathrm{mmHg}\end{array}$ & $73.0 \pm 11.7$ & $74.6 \pm 8.6$ & 0.39 & 0.80 & 0.091 \\
\hline $\begin{array}{l}\text { Waist } \\
\text { circumference, } \\
\mathrm{cm}\end{array}$ & $85.5 \pm 6.6$ & $93.8 \pm 7.1$ & $<0.0001$ & 0.18 & 0.16 \\
\hline Waist-to-hip ratio & $0.88 \pm 0.05$ & $0.90 \pm 0.06$ & 0.013 & 0.87 & 0.14 \\
\hline Body fat, $\%$ & $29.3 \pm 4.4$ & $39.5 \pm 3.3$ & $<0.0001$ & $<0.0001$ & 0.080 \\
\hline Total body fat, $\mathrm{kg}$ & $19.1 \pm 4.2$ & $28.4 \pm 3.9$ & $<0.0001$ & $<0.0001$ & 0.98 \\
\hline $\begin{array}{l}\text { Android-to-gynoid } \\
\text { fat mass ratio }\end{array}$ & $0.36 \pm 0.12$ & $0.49 \pm 0.11$ & $<0.0001$ & 0.0003 & 0.57 \\
\hline $\begin{array}{l}\text { EVAT-to-total fat } \\
\text { mass ratio }\end{array}$ & $0.018 \pm 0.0078$ & $0.024 \pm 0.0092$ & 0.0002 & 0.0032 & 0.28 \\
\hline $\begin{array}{l}\text { Subcutaneous fat } \\
\text { cell volume, } \mathrm{pl}\end{array}$ & $255.7 \pm 84.9$ & $423.7 \pm 113.9$ & $<0.0001$ & $<0.0001$ & 0.15 \\
\hline $\begin{array}{r}\text { Fat cell number } \\
\text { within ESAT } \\
\text { region, } \times 10^{7}\end{array}$ & $403.7 \pm 158.4$ & $463.5 \pm 150.8$ & 0.027 & 0.75 & 0.33 \\
\hline
\end{tabular}

Absolute values (mean \pm standard deviations) and $P$ values, unadjusted and adjusted for BMI. $B M I$ body mass index, ESAT estimated subcutaneous adipose tissue, EVAT estimated visceral adipose tissue, HOMA-IR homeostasis model assessment of insulin resistance, $R Y G B$ Roux-en-Y gastric bypass

${ }^{\text {a }}$ Unpaired 2-sided $t$ test used when normally distributed otherwise Mann-Whitney $U$ test

${ }^{\mathrm{b}}$ Multiple regression analyses adjusting for BMI (patients with anti-hypertensive treatment or lipid-lowering medication excluded when applicable)

${ }^{\mathrm{c}} P$ value for interaction between body fat $\%$ and BMI

d 2-tailed Fisher's exact test

group ( $P=0.19)$, but the between-group differences were still seen for triglycerides $(P=0.018), M$ value $(P=0.0044)$, EVAT-to-total fat mass ratio $(P=0.011)$, android-to-gynoid ratio $(P=0.0007)$, and fat cell volume $(P<0.0001)$ but not for HOMA-IR ( $P=0.091)$. To investigate the impact on insulin sensitivity ( $M$ value), separate multiple regression analyses were performed with the statistically significant adipose tissue parameters (subcutaneous adipocyte volume and android-to- 
a.

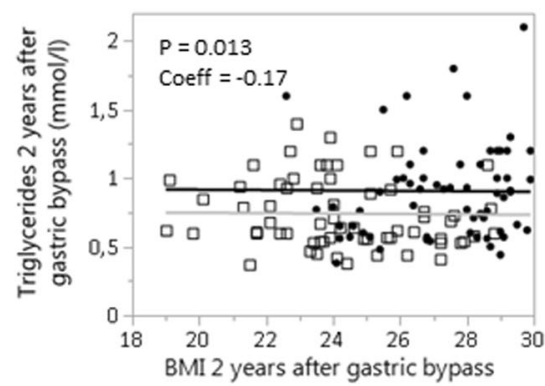

d.

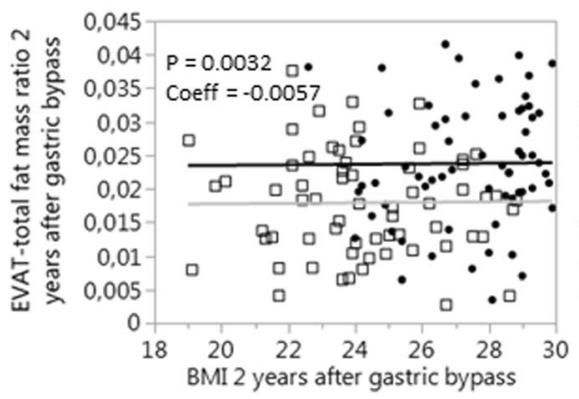

b.

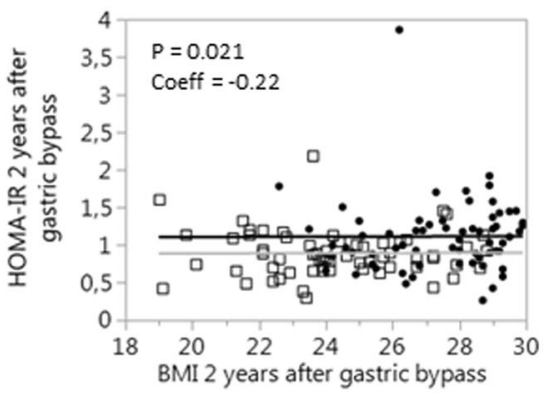

C.

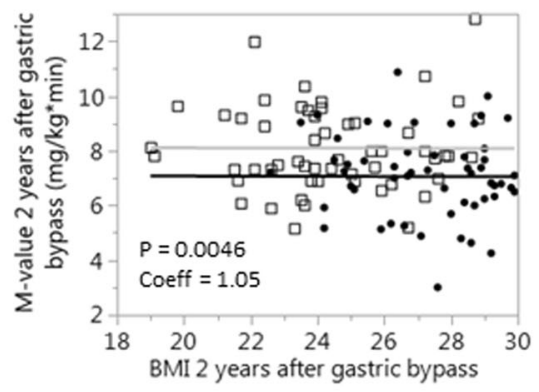

e.

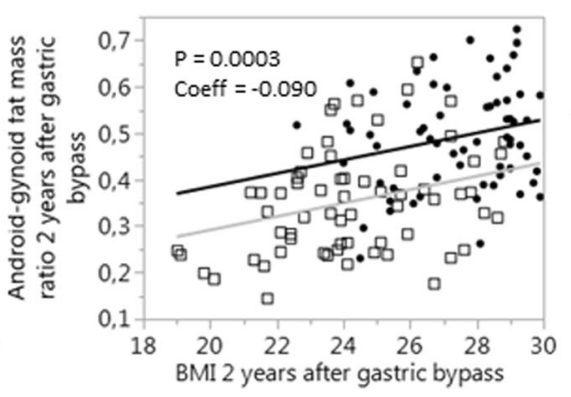

f.

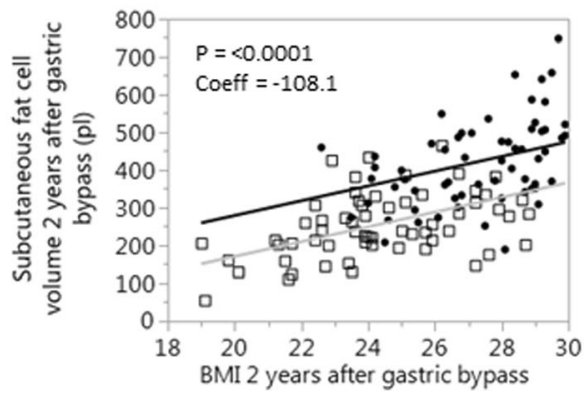

Fig. 3 Triglyceride concentration (a), insulin sensitivity (b, c), body fat distribution (d, e), and subcutaneous fat cell volume (f) in women with high ( $\geq 35 \%$, dots/black line) versus low $(<35 \%$, squares/gray line) body fat percentage 2 years after gastric bypass, with body mass index as covariate in multiple regression analyses. $P$ values and coefficients for body fat percentage. EVAT, estimated visceral adipose tissue; HOMA-IR, homeostasis model assessment of insulin resistance gynoid and EVAT-to-total fat mass ratios) combined with high/low BF\% and BMI as covariates (Table 2). These analyses showed that android-to-gynoid fat mass ratio $(P=0.0008)$ and subcutaneous fat cell volume $(P=0.0013)$ predicted $M$ value independently of BMI and BF\%, whereas EVAT-tototal fat mass ratio did not $(P=0.20)$.

\section{Conclusion}

In this study, we demonstrate that high $\mathrm{BF} \%$ in women with obesity remission after RYGB is associated with reduced insulin sensitivity, higher TG concentration, and a more unfavorable body fat distribution, independent of BMI. No statistically significant differences in fasting glucose, waist circumference, or waist-to-hip ratio were observed between patients with low and high $\mathrm{BF} \%$. These findings indicate that patients with high BF\% may not be identified by these measures or BMI at follow-up after RYGB.

Several cross-sectional studies have reported on the discrepancies between BMI and BF\% [4]. However, to the best of our knowledge, only one study has previously investigated this phenomenon in the long-term follow-up after RYGB [25]. In that study, Gómez-Ambrosi et al. compared BMI and BF\% versus metabolic parameters after RYGB [3]. In line with our findings, they reported higher visceral fat content and $\mathrm{TG}$ concentration among women with higher body fat, but not with higher BMI. However, they also found differences in total and LDL cholesterol between women with low versus high body fat which were not observed in our study. Moreover, Gómez-Ambrosi et al. also included patients within the obese BMI range which may have influenced their results. Further differences between the studies were that our study focused on the BMI-independent impact of high BF\% in the non-obese range after RYGB, that we used DXA to measure $\mathrm{BF} \%$ and body fat distribution, and that we determined adipocyte size and number and measured insulin sensitivity by hyperinsulinemic clamp.

Although BMI is an easily assessed anthropometric measure, the findings herein display the limitations of this variable as a proxy for excess fat accumulation and its metabolic effects after bariatric surgery. The clinical impact of the between-group difference in insulin sensitivity observed at the follow-up 2 years after surgery may seem limited, with relatively small differences and average insulin sensitivity values still within the normal range in both groups. However, weight regain and deteriorated glucose control might be expected another couple of years after RYGB [9, 15]. In the long term, patients with high $\mathrm{BF} \%$ may therefore be particularly vulnerable to recurrence of disturbed glucose metabolism or incident type 2 diabetes, a matter of further investigation in longitudinal cohorts. Moreover, patients with 
Table 2 BMI-independent impact of body fat percentage and adipose tissue covariates as determinants of insulin sensitivity. Multiple regression analyses with $M$ value $(\mathrm{mg} / \mathrm{kg} \times \mathrm{min})$ as dependent variable versus body fat percentage (BF\%, $\geq$ or $<35)$, body mass index (BMI), and different covariates as independent variables. All variables measured 2 years after gastric bypass in women with obesity remission. $P$ values/ standard beta coefficients (std beta). EVAT estimated visceral adipose tissue

\begin{tabular}{llll}
\hline Covariate & $\begin{array}{l}\text { Covariate } \\
P \text { value/std beta }\end{array}$ & $\begin{array}{l}\text { BF\% } \\
P \text { value/std beta }\end{array}$ & $\begin{array}{l}\text { BMI } \\
P \text { value }\end{array}$ \\
\hline Android-to-gynoid fat mass ratio, $n=108$ & $0.0008 /-0.37$ & 0.098 & 0.38 \\
EVAT-to-total fat mass ratio, $n=108$ & 0.20 & $0.019 / 0.28$ & 0.99 \\
Subcutaneous fat cell volume, $n=100$ & $0.0013 /-0.43$ & 0.19 & 0.14 \\
\hline
\end{tabular}

higher body fat displayed larger subcutaneous fat cells size which is known to predict the development of type 2 diabetes [26, 27].

We have previously reported that adipose tissues after weight reduction to a non-obese state display a more benign phenotype than in matched controls [16]. Many weight lossindependent mechanisms after RYGB, including incretin effects [17], are known to contribute to metabolic improvement and the metabolic impact of excess fat mass in the post-obese state after RYGB could therefore be limited. However, our findings show that relative fat mass remains a determinant of insulin sensitivity in the post-obese state, independent of BMI and age. Since no difference in insulin stimulated glucose uptake was found when normalized for lean body mass, differences in muscle mass are probably a contributor to the differences in whole body glucose disposal rate observed. However, a less favorable fat distribution and larger subcutaneous fat cell size may also be of importance. Our results demonstrate that larger subcutaneous fat mass depot is explained by adipocyte hypertrophy, i.e., increased fat cell size but not number, a phenomenon known to be linked to lower insulin sensitivity $[23,28]$. In contrast to the observed differences in insulin sensitivity, body fat mass did not seem to be a major determinant of blood pressure or blood lipid levels in these post-obese patients. These disturbances may instead be more dependent on other factors.

The strengths of this study include that a relatively large and well characterized cohort was studied, with insulin sensitivity determined by two measures with consistent results. Furthermore, we used DXA to determine total and regional fat mass. The US Food and Drug Administration has approved this assessment of visceral fat for clinical use, and it is validated against reference methods such as computed tomography [29]. Limitations of this study include the fact that only women were investigated. Unfortunately, we have not been able to recruit enough men to allow for sex-specific analyses which would also require different cut-offs for high/low BF\% in men. When interpreting the results, one should also bear in mind that the vast majority of women in this cohort were not diagnosed with type 2 diabetes before surgery. It is thus not known whether the findings could be generalized to men or patients with type 2 diabetes undergoing RYGB. The rationale behind using the $35 \%$ body fat cutoff point has been discussed [30] since there are no universally accepted definition of obesity based on body fat mass [4]. However, this threshold has been commonly used to define obesity based on body fat in previous studies [2, 3].

To conclude, higher BF\% not reflected by BMI in the non-obese state after RYGB is accompanied by lower insulin sensitivity and higher triglyceride levels in women. Low muscle mass, android fat accumulation, and large subcutaneous fat cells may contribute to the decreased insulin sensitivity observed. Determination of insulin sensitivity, $\mathrm{BF} \%$, or body fat distribution at the follow-up after RYGB in women may add information on the metabolic status in women that have reached a non-obese state after RYGB. Whether patients with high body fat percentage independent of BMI after RYGB may be more prone to redevelopment of metabolic disturbances is a matter for future studies.

Acknowledgments Open access funding provided by Karolinska Institute. The authors are grateful for the skillful assistance of research nurses Katarina Hertel, Yvonne Widlund, and Britt-Marie Leijonhufvud as well as laboratory technicians Kerstin Wåhlén and Elisabeth Dungner at the Lipid laboratory, Department of Medicine, Karolinska Institutet, Huddinge, Sweden.

Funding This study was financially supported by The Erling-Persson Family Foundation (AT), The SRP Rolf Luft Clinical Research Grant (DA), The Swedish Society of Medicine (DA), and Stockholm County Council (DEH K1142-2014, JB 20150666, DA K0138-2015).

\section{Compliance with Ethical Standards}

Conflict of Interest The authors declare that they have no conflict of interest.

Ethical Approval All procedures performed in studies involving human participants were in accordance with the ethical standards of the institutional and/or national research committee and with the 1964 Helsinki declaration and its later amendments or comparable ethical standards. The local ethical committee has approved the study. 
Informed Consent Informed consent was obtained from all individual participants included in the study.

Open Access This article is distributed under the terms of the Creative Commons Attribution 4.0 International License (http:// creativecommons.org/licenses/by/4.0/), which permits unrestricted use, distribution, and reproduction in any medium, provided you give appropriate credit to the original author(s) and the source, provide a link to the Creative Commons license, and indicate if changes were made.

\section{References}

1. World Health Organization. Fact sheets/Obesity and overweight [Internet]. Geneva, Switzerland: World Health Organization; 2018 [updated 2018 February 16; cited 2019 April 23]. Available from: http://www.who.int/news-room/fact-sheets/detail/obesity-andoverweight.

2. Romero-Corral A, Somers VK, Sierra-Johnson J, et al. Accuracy of body mass index in diagnosing obesity in the adult general population. Int J Obes. 2008;32(6):959-66.

3. Gomez-Ambrosi J, Silva C, Galofre JC, et al. Body mass index classification misses subjects with increased cardiometabolic risk factors related to elevated adiposity. Int J Obes. 2012;36(2):286-94.

4. Okorodudu DO, Jumean MF, Montori VM, et al. Diagnostic performance of body mass index to identify obesity as defined by body adiposity: a systematic review and meta-analysis. Int J Obes. 2010;34(5):791-9.

5. De Lorenzo A, Bianchi A, Maroni P, et al. Adiposity rather than BMI determines metabolic risk. Int J Cardiol. 2013;166(1):111-7.

6. Berg C, Strandhagen E, Mehlig K, et al. Normal weight adiposity in a Swedish population: how well is cardiovascular risk associated with excess body fat captured by BMI? Obes Sci Pract. 2015;1(1): 50-8.

7. Jo A, Mainous 3rd. AG. Informational value of percent body fat with body mass index for the risk of abnormal blood glucose: a nationally representative cross-sectional study. BMJ Open. 2018;8(4):e019200.

8. Zhao T, Lin Z, Zhu H, et al. Impact of body fat percentage change on future diabetes in subjects with normal glucose tolerance. IUBMB Life. 2017;69(12):947-55.

9. Sjostrom L. Review of the key results from the Swedish Obese Subjects (SOS) trial - a prospective controlled intervention study of bariatric surgery. J Intern Med. 2013;273(3):219-34.

10. Mingrone G, Panunzi S, De Gaetano A, et al. Bariatric-metabolic surgery versus conventional medical treatment in obese patients with type 2 diabetes: 5 year follow-up of an open-label, singleCentre, randomised controlled trial. Lancet. 2015;386(9997):964 73.

11. Schauer PR, Bhatt DL, Kirwan JP, et al. Bariatric surgery versus intensive medical therapy for diabetes - 5-year outcomes. N Engl J Med. 2017;376(7):641-51.

12. National Institutes of Health. Gastrointestinal surgery for severe obesity. NIH Consens Statement 1991; 9(1): 1-20. [Internet] Bethesda, Maryland, USA: National Institutes of Health; 1991 [cited 201910 01] Available from: https://consensus.nih.gov/1991/ 1991 gisurgeryobesity084html.htm.

13. De Luca M, Angrisani L, Himpens J, et al. Indications for surgery for obesity and weight-related diseases: position statements from the International Federation for the Surgery of Obesity and Metabolic Disorders (IFSO). Obes Surg. 2016;26(8):1659-96.

14. Mocanu V, Nasralla A, Dang J, et al. Ongoing inconsistencies in weight loss reporting following bariatric surgery: a systematic review. Obes Surg. 2019;29(4):1375-87.

15. Hoffstedt J, Andersson DP, Eriksson Hogling D, et al. Long-term protective changes in adipose tissue after gastric bypass. Diabetes Care. 2017;40(1):77-84.

16. Andersson DP, Dahlman I, Eriksson Hogling D, et al. Improved metabolism and body composition beyond normal levels following gastric bypass surgery: a longitudinal study. J Intern Med. 2019;285(1):92-101.

17. Laferrere B, Pattou F. Weight-independent mechanisms of glucose control after Roux-en-Y gastric bypass. Front Endocrinol (Lausanne). 2018;9:530.

18. Andersson DP, Thorell A, Lofgren P, et al. Omentectomy in addition to gastric bypass surgery and influence on insulin sensitivity: a randomized double blind controlled trial. Clin Nutr. 2014;33(6): 991-6.

19. Andersson DP, Eriksson-Hogling D, Backdahl J, et al. Omentectomy in addition to bariatric surgery-a 5-year follow-up. Obes Surg. 2017;27(4):1115-8.

20. Eriksson Hogling D, Ryden M, Backdahl J, et al. Body fat mass and distribution as predictors of metabolic outcome and weight loss after Roux-en-Y gastric bypass. Surg Obes Relat Dis. 2018;14(7): 936-42.

21. Rodbell M. Metabolism of isolated fat cells. I. Effects of hormones on glucose metabolism and lipolysis. J Biol Chem. 1964;239:37580 .

22. Matthews DR, Hosker JP, Rudenski AS, et al. Homeostasis model assessment: insulin resistance and beta-cell function from fasting plasma glucose and insulin concentrations in man. Diabetologia. 1985;28(7):412-9.

23. Hoffstedt J, Arner E, Wahrenberg H, et al. Regional impact of adipose tissue morphology on the metabolic profile in morbid obesity. Diabetologia. 2010;53(12):2496-503.

24. Friedewald WT, Levy RI, Fredrickson DS. Estimation of the concentration of low-density lipoprotein cholesterol in plasma, without use of the preparative ultracentrifuge. Clin Chem. 1972;18(6):499 502.

25. Gomez-Ambrosi J, Andrada P, Valenti V, et al. Dissociation of body mass index, excess weight loss and body fat percentage trajectories after 3 years of gastric bypass: relationship with metabolic outcomes. Int J Obes. 2017;41(9):1379-87.

26. Weyer C, Foley JE, Bogardus C, et al. Enlarged subcutaneous abdominal adipocyte size, but not obesity itself, predicts type II diabetes independent of insulin resistance. Diabetologia. 2000;43(12): 1498-506.

27. Lonn M, Mehlig K, Bengtsson C, et al. Adipocyte size predicts incidence of type 2 diabetes in women. FASEB J. 2010;24(1): 326-31.

28. Eriksson-Hogling D, Andersson DP, Backdahl J, et al. Adipose tissue morphology predicts improved insulin sensitivity following moderate or pronounced weight loss. Int J Obes. 2015;39(6):893-8.

29. Kaul S, Rothney MP, Peters DM, et al. Dual-energy X-ray absorptiometry for quantification of visceral fat. Obesity (Silver Spring). 2012;20(6):1313-8.

30. Ho-Pham LT, Campbell LV, Nguyen TV. More on body fat cutoff points. Mayo Clin Proc. 2011;86(6):584. author reply 584-5

Publisher's Note Springer Nature remains neutral with regard to jurisdictional claims in published maps and institutional affiliations. 